\title{
Circadian Control of Global Isoprene Emissions
}

\section{Citation}

Keenan, Trevor F. and U. Niinemets. 2012. Circadian control of global Isoprene emissions. Nature Geoscience 5(7): 453.

\section{Published Version}

doi:10.1038/ngeo1500

\section{Permanent link}

http://nrs.harvard.edu/urn-3:HUL.InstRepos:10622401

\section{Terms of Use}

This article was downloaded from Harvard University's DASH repository, and is made available under the terms and conditions applicable to Other Posted Material, as set forth at http:// nrs.harvard.edu/urn-3:HUL.InstRepos:dash.current.terms-of-use\#LAA

\section{Share Your Story}

The Harvard community has made this article openly available.

Please share how this access benefits you. Submit a story.

Accessibility 


\section{Circadian control of global isoprene emissions}

Nature Geoscience

Keenan, T.F. , Niinemets, Ü.\#

* Department of Organismic and Evolutionary Biology, Harvard University, Cambridge MA, 02138 USA.

${ }^{\#}$ Institute of Agricultural and Environmental Sciences, Estonian University of Life Sciences, Kreutzwaldi 1, Tartu 51014, Estonia

Hewitt et al. ${ }^{1}$ reported the detection of circadian control of isoprene emissions from two tropical rainforests in Malaysia, based on their finding that a model without a circadian control cannot reproduce the observations. By including circadian controlled isoprene emissions into models of atmospheric chemistry and transport, they suggested that plant circadian rhythms indirectly affect the global concentration of surface level ozone. Here we argue that the circadian rhythm postulated by Hewitt et al. ${ }^{1}$ is not robust, and depends on untested assumptions regarding both the temperature and light response of isoprene emissions, and the unaccounted for effects of canopy structure. We show that the apparent circadian control disappears if different, biologically realistic, model parameters are used.

In the Hewitt et al. study, they used the Guenther et al. ${ }^{2}$ algorithms of the MEGAN ${ }^{2}$ model to detect the circadian control. We base our hypothesis on the notion that non-random deviations of the model parameters from their unknown true value can lead to an apparent circadian rhythm. We tested our hypothesis using the same algorithms ${ }^{2}$ used by Hewitt et al., applying a Bayesian model inversion to synthetic data (See Fig. 1).

The optimized MEGAN model proved flexible enough to reproduce the synthetic circadian emissions with changes in parameters within parameter uncertainty, and no circadian control (Fig. 1). The net effect of the parameter changes was a shift in the relative importance of radiation in comparison to temperature in the control of isoprene emissions. So why would the Malaysian forests have a different light and temperature response curve to that included in MEGAN?

There are various isoprene emissions models available, and the shape of the light and temperature response curves of each is decidedly different ${ }^{3}$. This reflects significant variations in light and temperature responses of isoprene emissions within and across species, due to interspecific variations in isoprene synthase expression and differences in dynamic substrate pools ${ }^{4}$. It may, therefore, not be reasonable to expect the dependencies applied in MEGAN, estimated from leaves of temperate forests ${ }^{2}$, to apply to Malaysian rainforest canopies.

In addition, all isoprene models are leaf-level models that are later scaled to the canopy, thereby being highly sensitive to assumptions regarding canopy structure ${ }^{5,6}$. The extraction of basal emissions at a canopy scale is complicated both by strong diurnal gradients in canopy micrometeorology and the high variability of basal emissions rates within the canopy itself ${ }^{7}$. To 
adhere with the Hewitt et al. study, we have used their isoprene model without detailing canopy structure, albeit this is another potential factor that could change the expected diurnal pattern of whole-canopy emissions, e.g., by altering the contributions of different foliage layers to total canopy emissions.

We agree with Hewitt et al. that isoprene emission models should be improved, but we show here that the diurnal response of isoprene emissions in their study cannot be conclusively attributed to a circadian control. Although a leaf-level circadian and ultradian controls have been previously reported ${ }^{8,9}$, we argue that the extent to which this effects canopy scale emissions has yet to be rigorously assessed. Clearly more work is needed to gain insight into variations of light and temperature responses of isoprene emissions across the globe. Model optimization techniques ${ }^{10}$ such as those used here could aid in quantifying the extent of natural variability, and the associated implications for modeling global isoprene emissions.

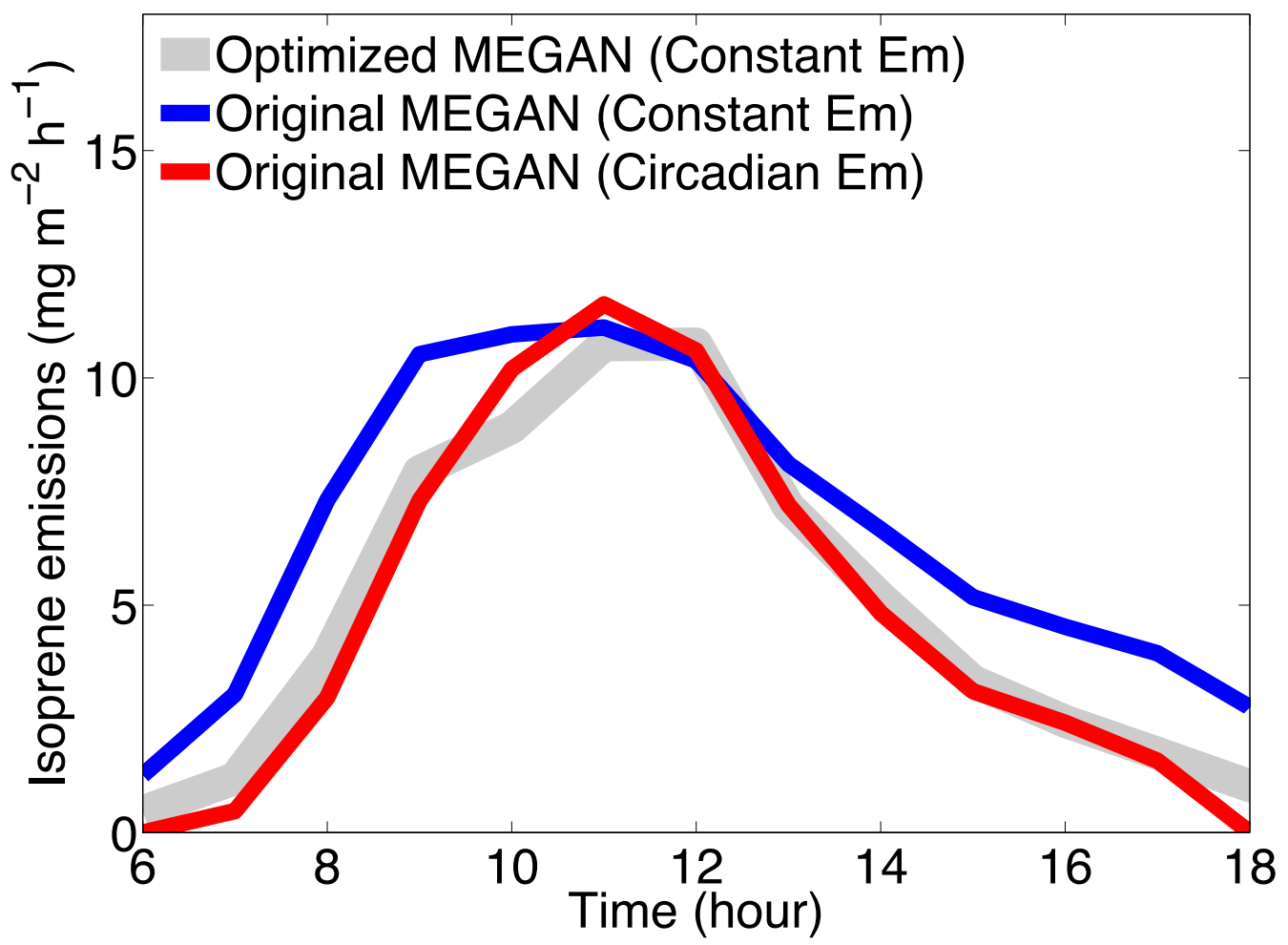

The three lines represent the three steps in the test of our hypothesis. First we generated a Fig. 1 synthetic emissions time series using the standard MEGAN model with a constant basal emission rate (Blue, Original MEGAN with constant Em). We then generated a 'circadian' time series using MEGAN, by assuming a circadian basal emission rate (Hewitt et al. Eq. S7) (Red, Original MEGAN, Circadian Em). Finally, we optimized the parameters of the MEGAN model using Markov-chain Monte Carlo with simulated annealing, and tested whether the 'circadian' time series can be modeled without circadian control (i.e., a fixed basal emission rate, but slightly different model parameters). Parameter values were allowed to vary by $30 \%$, which is well within observed and biologically realistic variability ${ }^{11}$. (Gray, Optimized MEGAN, Constant Em). See Hewitt et al. Fig.S1b for comparison. 
1. Hewitt, C.N. et al. Ground-level ozone influenced by circadian control of isoprene emissions. Nature Geoscience 4, 671-674 (2011).

2. Guenther, A. et al. Estimates of global terrestrial isoprene emissions using MEGAN (Model of Emissions of Gases and Aerosols from Nature). Atmospheric Chemistry and Physics 6, 3181-3210 (2006).

3. Arneth, A. et al. Process-based estimates of terrestrial ecosystem isoprene emissions: incorporating the effects of a direct CO 2-isoprene interaction. Atmospheric Chemistry and Physics 7, 31-53 (2007).

4. Niinemets, Ü. et al. The leaf-level emission factor of volatile isoprenoids: caveats, model algorithms, response shapes and scaling. Biogeosciences 7, 1809-1832 (2010).

5. Grote, R. Sensitivity of volatile monoterpene emission to changes in canopy structure: a model-based exercise with a process-based emission model. New phytologist 173, 550-61 (2007).

6. Keenan, T.F., Grote, R. \& Sabaté, S. Overlooking the canopy: The importance of canopy structure in scaling isoprenoid emissions from the leaf to the landscape. Ecological Modelling 222, 737-747 (2011).

7. Niinemets, Ü., Copolovici, L. \&Hüve, K. High within-canopy variation in isoprene emission potentials in temperate trees: Implications for predicting canopy-scale isoprene fluxes. Journal of Geophysical Research 115, G04029, doi:10.1029/2010JG001436 (2010).

8. Wilkinson, M.J. et al. Circadian control of isoprene emissions from oil palm (Elaeis guineensis). The Plant Journal, 47, 960-8 (2006).

9. Wiberley, A.E., Donohue, A.R., Westphal, M.M. \& Sharkey, T.D. Regulation of isoprene emission from poplar leaves throughout a day. Plant, Cell \& Environment, 32, 939-47 (2009).

10. e.g., Keenan, T.F., Carbone, M.S., Reichstein, M. \& Richardson, A.D. The model-data fusion pitfall: assuming certainty in an uncertain world. Oecologia 167, 587-597 (2011).

11. Langford, B., et al., Fluxes and concentrations of volatile organic compounds from a South-East Asian tropical rainforest. Atmospheric Chemistry \& Physics, 10, 8391-8412 (2010). 